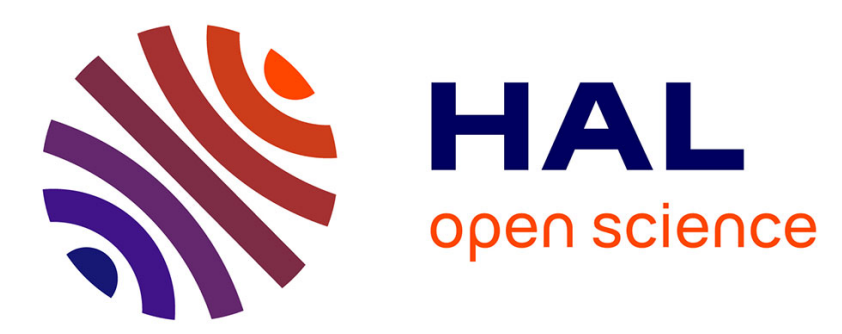

\title{
Modeling of Inhomogeneous 4H-SiC Schottky and JBS Diodes in a Wide Temperature Range
}

\author{
Besar Asllani, Maxime Berthou, Dominique Tournier, Pierre Brosselard, \\ Phillippe Godignon
}

\section{> To cite this version:}

Besar Asllani, Maxime Berthou, Dominique Tournier, Pierre Brosselard, Phillippe Godignon. Modeling of Inhomogeneous 4H-SiC Schottky and JBS Diodes in a Wide Temperature Range. Materials Science Forum, 2016, 858, pp.741 - 744. 10.4028/www.scientific.net/MSF.858.741 . hal-01646323

\section{HAL Id: hal-01646323 \\ https://hal.science/hal-01646323}

Submitted on 10 Jan 2018

HAL is a multi-disciplinary open access archive for the deposit and dissemination of scientific research documents, whether they are published or not. The documents may come from teaching and research institutions in France or abroad, or from public or private research centers.
L'archive ouverte pluridisciplinaire HAL, est destinée au dépôt et à la diffusion de documents scientifiques de niveau recherche, publiés ou non, émanant des établissements d'enseignement et de recherche français ou étrangers, des laboratoires publics ou privés. 


\title{
Modeling of inhomogeneous 4H-SiC Schottky and JBS diodes in a wide temperature range
}

\author{
Besar Asllani ${ }^{1, a^{*}}$, Maxime Berthou ${ }^{1, b}$, Dominique Tournier ${ }^{1, c}$, \\ Pierre Brosselard ${ }^{2, \mathrm{~d}}$ and Philippe Godignon ${ }^{3, \mathrm{e}}$ \\ ${ }^{1}$ Laboratoire Ampère, 21 Av Capelle Ouest, 69621 Villeurbanne Cédex, France \\ ${ }^{2}$ CALY Technologies, 56 Bd Niels Bohr, 69603 Villeurbanne Cédex, France \\ ${ }^{3}$ Centro Nacional de Microelectronica, Calle del Tillers, 08193, Bellatera (Barcelona), Espana \\ abesar.asllani@insa-lyon.fr, ${ }^{b}$ maxime.berthou@insa-lyon.fr, 'dominique.tournier@insa-lyon.fr, \\ dp.brosselard@caly-technologies.com, ephilippe.godignon@imb-cnm.csic.es
}

Keywords: 4H-SiC, Schottky diodes, JBS, Richardson constant, Barrier height temperature dependance, partial ionisation.

Abstract. This paper presents a study of the Schottky barrier evolution on SBD and JBS diodes over a wide range of temperatures from 80 to $500 \mathrm{~K}$. We show that inhomogeneities of the Schottky contact have a strong impact on the dependence of barrier characteristics with temperature, especially below $200 \mathrm{~K}$. Analysis of the reverse bias current of such diodes at low temperature show that the barrier height depends on temperature but also on voltage.

\section{Introduction}

4H-SiC SBD and JBS diodes have shown high voltage and commutation capabilities. These components are already commercially available and outrun Si PiN diodes of same caliber. Many studies prove that Schottky contact is yet a challenge since we cannot fully explain the deviation between theoretical and measured Richardson constant. This difference has been attributed to the inhomogeneity of the contact, which would lead to areas of different barrier height of the Schottky contact. These areas become more or less active depending on the operating temperature and the applied voltage. This particular behavior prevents from easily modeling the Schottky contact in reverse bias.

\section{Experimental setup}

For a better understanding of the Schottky contact we have characterized a variety of commercial and experimental devices listed in the Table I. The measurements were performed in a cryogenic vacuum chamber from 80 to $500 \mathrm{~K}$ at $10 \mu \mathrm{bar}$, allowing a temperature precision of $0.1^{\circ}$. We performed IVT and CVT on a relevant number of components, which revealed unreported results. Electrical characterizations were performed with an Agilent B1505A.

Table I. Components characterized for this study

\begin{tabular}{|c|c|c|c|c|c|c|}
\hline \multirow{2}{*}{ Device } & \multirow{2}{*}{ Reference } & \multirow{2}{*}{ Type } & \multirow{2}{*}{ Area } & \multicolumn{3}{|c|}{ Electrical spec } \\
\hline & & & & $\begin{array}{l}\text { Blocking } \\
\text { voltage }\end{array}$ & $\begin{array}{l}\text { Forward } \\
\text { current }\end{array}$ & $\begin{array}{l}\text { Reverse current } \\
\text { @VBR@300K }\end{array}$ \\
\hline A & CNM BEPI & SBD & $4.41 \mathrm{~mm} 2$ & $300 \mathrm{~V}$ & $5 \mathrm{~A}$ & $0.4 \mu \mathrm{A} \mathrm{cm}-2$ \\
\hline B & CNM ALS & JBS & $4.41 \mathrm{~mm} 2$ & $1200 \mathrm{~V}$ & $5 \mathrm{~A}$ & $1.3 \mathrm{~mA} \mathrm{~cm}-2$ \\
\hline $\mathrm{C}$ & CREE CSD01060A & SBD & $0.5 \mathrm{~mm} 2$ & $600 \mathrm{~V}$ & $2.2 \mathrm{~A}$ & $14 \mu \mathrm{A} \mathrm{cm}-2$ \\
\hline $\mathrm{D}$ & CREE C4D20120A & SBD & $1.2 \mathrm{~mm} 2$ & $1200 \mathrm{~V}$ & $5.9 \mathrm{~A}$ & $65 \mu \mathrm{A} \mathrm{cm}-2$ \\
\hline
\end{tabular}




\section{Forward bias IVT and CVT measurement results}

The forward bias characterization of all the families of components has given homogeneous curve spreading from 80 up to $500 \mathrm{~K}$. Figure 1 resumes the forward characteristic of device D, where we can see a homogeneous variation of the barrier height in the temperature range. The barrier height has been extracted from IVT and CVT curves at different temperatures. As we can observe in figure 2, barrier height can be extracted at $0 \mathrm{~V}$ bias from $\mathrm{CV}$ measurements. This yields in our case an average value of $0.4 \mathrm{eV}$ higher than the ones extracted from IV $(1.23 \mathrm{eV}$ at $300 \mathrm{~K}$ for device $\mathrm{C}$ ). The difference [4] is observed due to a flat band behavior.

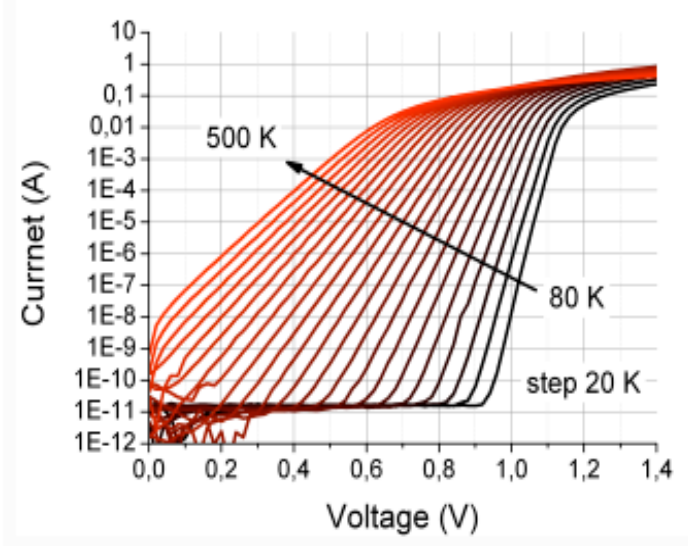

Fig. 1 - Forward bias characterization of device C.

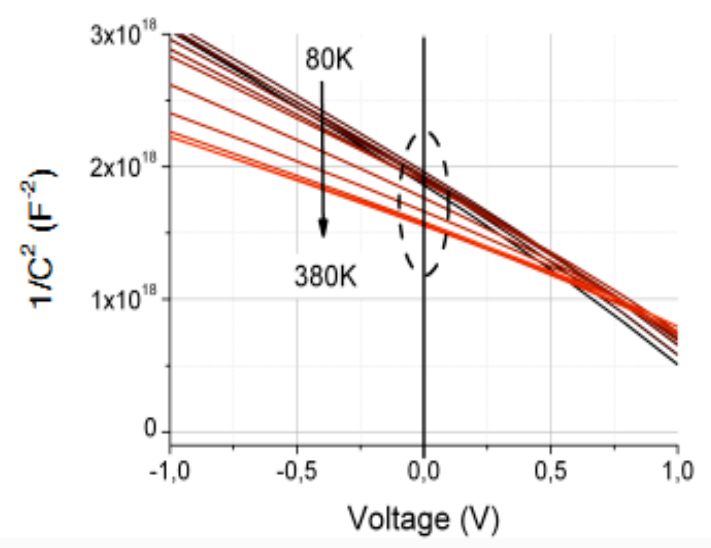

Fig. 2 - Low voltage $1 / \mathrm{C}^{2}$ measurement on device $\mathrm{B}$.

Barrier height and ideality factor extracted from devices of group $\mathrm{C}$, are plotted in figure 3 as functions of temperature. As we can see, the evolution of these two physical parameters can be modeled as a linear function of $1 / \mathrm{T}$.

The variation of these physical parameters has been attributed to the Schottky contact inhomogeneities [2] and has been modeled as a distribution of small patches of low barrier height that interact with the surrounding high barrier areas. Arrhenius plot is used to obtain the experimental value of Richardson constant. In our case, the Arrhenius plot yields a value of 6 $\mathrm{A} / \mathrm{cm}^{2} \mathrm{~K}^{2}$ for 0.3 to $0.6 \mathrm{~V}$ biases, which is 25 times lower than the theoretical value [3]. For higher bias the value obtained is even lower. Inhomogeneities of the contact can lead to such deviation from theory [5]. The interaction between different barrier patches is lowered at low temperature, which means low barrier patches are no more screened by the surrounding area due to partial ionization. In this case the majority of the current flows through the low barrier patches and the active area of the device is smaller than expected. To obtain the correct value of the Richardson constant a correction term related to partial ionization must be introduced in equation (1) to balance the surface reduction.

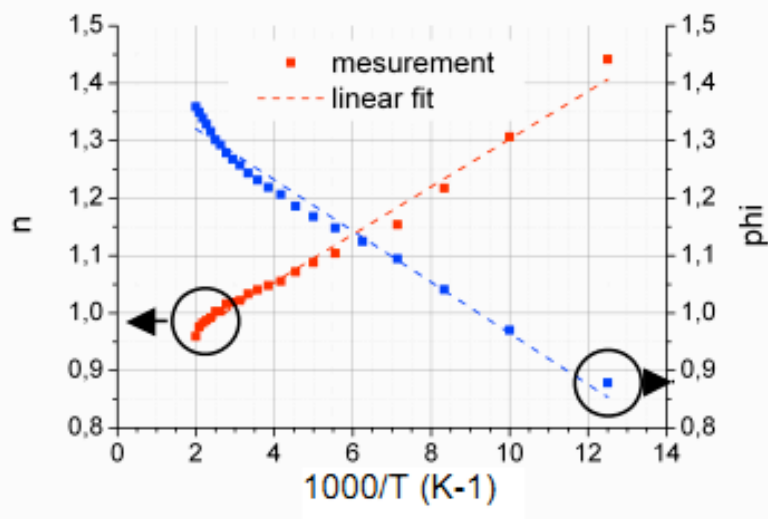

Fig. 3 - Dependence of ideality factor and barrier height versus temperature.

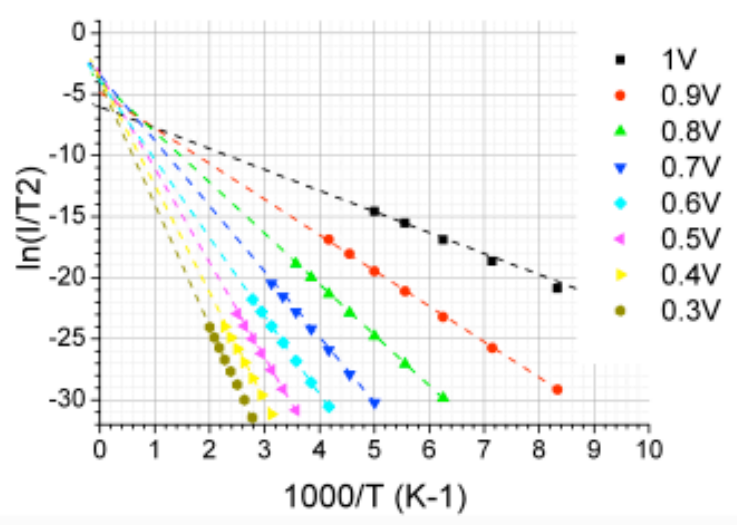

Fig. 4 - Arrhenius plot drawn for various biases. 


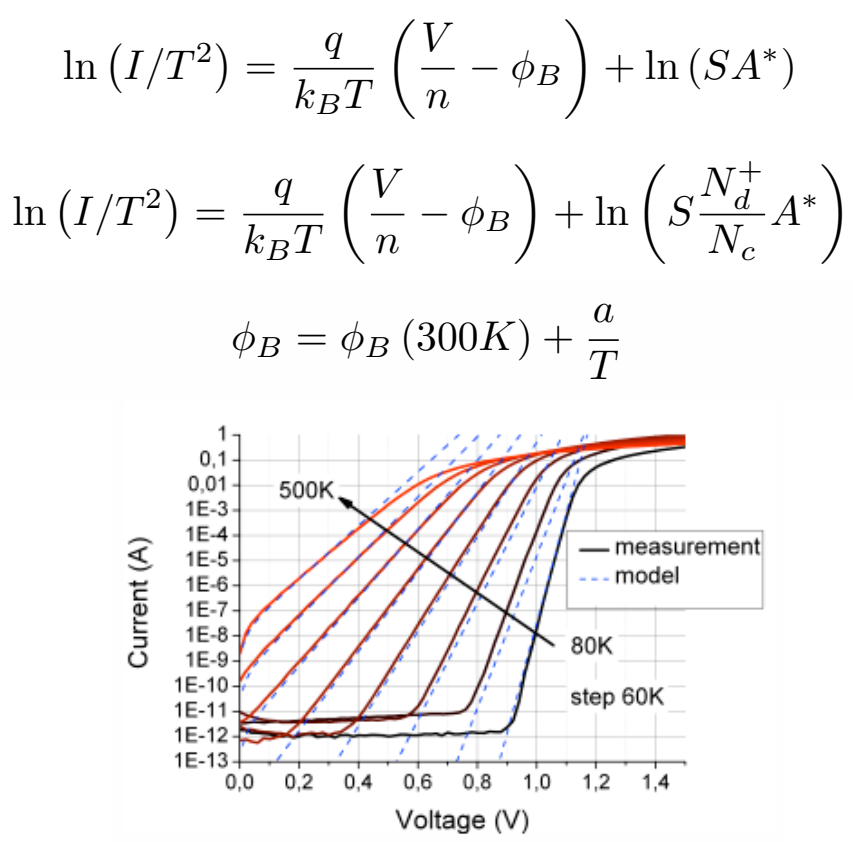

Fig. 5 - Forward bias measurement vs. new fitting technique of device $\mathrm{C}$.

Previous temperature dependent model of the Schottky barrier was used to model the forward IVT characteristics below the threshold voltage as shown in Figure 5 for device C. We can see that the model perfectly fits the measurements from 80 to $500 \mathrm{~K}$. Slight deviation is visible at low temperature, which may be improved with a more refined model in the future. Above the voltage threshold, adding the resistive contribution of the drift layer and contacts will be sufficient to fully model the IVT characteristics.

\section{Reverse bias IVT measurement results}

IV reverse bias measurements of the previous devices were performed in the range of 80 to $500 \mathrm{~K}$ and gave unreported results as shown in figure 6 . Under $700 \mathrm{~V}$ low temperature currents slowly decrease with the increasing temperature from 80 to $200 \mathrm{~K}$. From 200 to $500 \mathrm{~K}$ currents slowly increase with temperature. This creates an overlapped characteristic as evidenced by the dashed circle in figure 6 . Bias voltage restores the barrier height slowly until almost $600 \mathrm{~V}$. Then barrier height is modified only by the image force effect [7]. Using equation (3) in the analytical model did not fit the experimental results.

Consider Tung's theory [2] where interaction of small patches of low barrier height with the surrounding area modulates the current flow through the small patches in a pinch-off effect. The surface of the patches, the operating temperature and the bias voltage affect the diode in a JFET way pinching the current channel under the low barrier patches. The pinching can be explained from the partial ionization theory. At very low temperature dopants are partially or

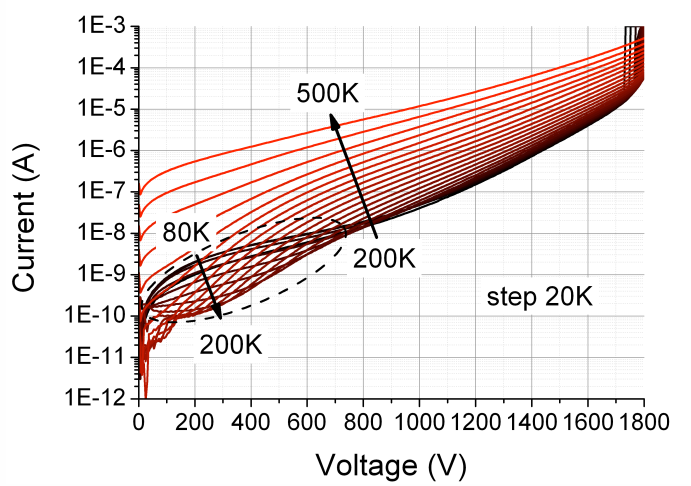

Fig. 6 - Reverse characteristic of device D. not ionized and the apparent doping of the drift region is much lower. The space charge zone under the high barrier areas is reduced. When the junction is biased, the electric field ionizes the dopants that deplete, increasing the space charge zone and obstructing the channels under the low barrier height areas.

This means that equation (3) has to be improved to mimic the variation of the barrier as a function of temperature and voltage. Expressing the barrier height as a sum of, flat band barrier height at room temperature, image force [7], and a temperature/voltage term we obtained the results 
shown in figure 7. The leakage currents of the simulated diode are modeled as a contribution of thermionic and field effect [6] current, which are reported as equation (4) and (5). The barrier

$$
\begin{gathered}
I_{T H}=S A T^{2} \exp \left(\frac{-q \phi_{B}}{k_{B} T}\right)\left[\exp \left(\frac{q V}{n k_{B} T}\right)-1\right] \\
I_{F E}=S A T\left(\frac{E_{00}}{k_{B}}\right)\left(\frac{\phi_{B}+V}{\phi_{B}}\right) \exp \left(\frac{-2 q \phi_{B}^{3 / 2}}{3 E_{00} \sqrt{\phi_{B}+V}}\right) \\
\phi_{B}=\phi_{B}(300 K)-\sqrt{\frac{q \xi}{4 \pi \epsilon}}+\frac{a}{T} \exp \left(\frac{b-V}{c+T}\right)
\end{gathered}
$$

height used for the calculation is obtained from equation (6).

\section{Conclusions}

IVT direct and reverse current characterizations were performed on a wide range of temperatures on various diodes. This study revealed unknown effects at low temperature for both barrier and leakage current characteristics. Barrier height dependence on temperature and bias voltage is confirmed. A temperature dependent model fits direct characteristic under the threshold voltage in the temperature range. A reverse leakage current model taking into account barrier height variation is proposed.

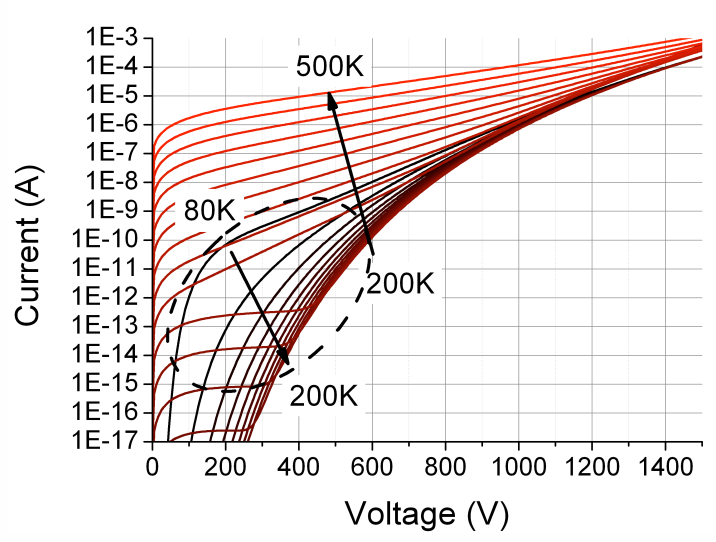

Fig. 7 - The result of the reverse leakage current model

\section{Acknowledgment}

The authors wish to thank for their financial support: the Caisse des Dépôts et Consignations (CDC) and BPI-France (FilSiC: Convention $\left.n^{\circ} \mathrm{O} 13953-410188\right)$. The authors will also thank $\mathrm{Mr}$. Grosset and Dupuy for the process of the devices at IBS.

\section{References}

[1] Berthou, M., Asllani, B., Brosselard, P., \& Godignon, P. Cryogenic to High Temperature Exploration of 4H-SiC W-SBD. Materials Science Forum 821 (2015) 583-587.

[2] Tung, R. T. Electron transport at metal-semiconductor interfaces: General theory. Phys. Rev. B 45.23 (1992) 13509.

[3] Roccaforte, F., La Via, f., Raineri, V., Pierobon, R., \& Zanoni,E. Richardson's constant in inhomogeneous silicon carbide Schottky contacts. J. Appl. Phys. 93.11 (2003) 9137.

[4] Itoh, A., Matsunami, H. \& Tred, Q. Analysis of Schottky Barrier Heights of Metal/SiC Contacts and Its Possible Application to High-Voltage Rectifying Devices. Phys. status solidi 162.1 (1997) 389-408.

[5] Werner, Jürgen, H., \& Herbert, H. Güttler. Barrier inhomogeneities at Schottky contacts. J. App. Phys. 69.3 (1991) 1522-1533.

[6] Padovani, F. A., \& R. Stratton. Field and thermionic-field emission in Schottky barriers. SolidState Electronics 9.7 (1966) 695-707.

[7] Cowley, A. M., and S. M. Sze. Surface states and barrier height of metal-semiconductor systems. Journal of Applied Physics 36.10 (1965) 3212-3220. 